\title{
TITLE:
}

\section{Cyclic transitions in simulated food-web evolution}

\section{$\operatorname{AUTHOR}(\mathrm{S})$ :}

Takahashi, Daisuke; Brännström, Åke; Mazzucco, Rupert; Yamauchi, Atsushi; Dieckmann, Ulf

\section{CITATION:}

Takahashi, Daisuke ... [et al]. Cyclic transitions in simulated food-web evolution. Journal of Plant Interactions 2011, 6(2-3): 181-182

\section{ISSUE DATE:}

2011-06

URL:

http://hdl.handle.net/2433/156885

\section{RIGHT:}

(c) 2011 Taylor \& Francis; This is not the published version. Please cite only the published version.; この論文は出版社版でありません。引用の 際には出版社版をご確認ご利用ください。 


\title{
Cyclic transitions in simulated food-web evolution
}

\author{
Daisuke TAKAHASHI ${ }^{1}$, Åke BRÄNNSTRÖM ${ }^{2}$, Rupert MAZZUCCO ${ }^{2}$, \\ Atsushi YAMAUCHI ${ }^{1,3}$, and Ulf DIECKMANN ${ }^{2}$
}

\author{
${ }^{1}$ Center for Ecological Research, Kyoto University, Hirano 2-509-3, Otsu 520-2113, Japan \\ ${ }^{2}$ Department of Mathematics and Mathematical Statistics, Umeå University, 90187 Umeå, Sweden \\ ${ }^{3}$ Evolution and Ecology Program, International Institute for Applied Systems Analysis, 2361 \\ Laxenburg, Austria \\ ${ }^{3}$ PRESTO, Japan Science and Technology Agency, Honcho 4-1-8, Kawaguchi 332-0012, Japan
}

\begin{abstract}
Eco-evolutionary food-web models help elucidate the processes responsible for the emergence and maintenance of complex community structures. Using an individual-based model of evolving trophic and competitive interactions, we highlight a pattern of community macroevolution involving two meta-stable states, corresponding to a plant-herbivore community and a plant community, respectively. On the evolutionary timescale, our model exhibits cyclic transitions between these alternative community states. The model also helps understand the eco-evolutionary mechanisms underlying these recurrent rapid transitions, which end intermittent periods of near-stasis or punctuated equilibrium.
\end{abstract}

Keywords: prey-predator interactions, trophic traits, evolution, community ecology

Interest is mounting in the evolutionary emergence of food-web structures. Understanding the processes that maintain or alter community structure offers valuable insights into the functioning of ecosystems, which may in turn facilitate the preservation of vulnerable natural systems. Several models have been proposed for analyzing the coevolutionary dynamics of exploiter-victim interactions (Drossel et al. 2001, 2004; Rossberg et al. 2006, 2008; see also models reviewed by Yoshida 2006). However, most of the existing models assume that community evolution proceeds by random speciation, and thus do not consider the gradual evolution of key functional traits. Ito and Ikegami (2006), Troost et al. (2008), and Ito et al. (2009) considered the gradual evolution of trait distributions; however, their models do not include stochastic fluctuations. Rossberg et al. (2010a) 
studied the gradual stochastic evolution and random speciation of trophic traits (Rossberg et al. 2010b) in predator-prey communities, but did not derive the examined evolutionary dynamics from the underlying population dynamics. Here, we introduce and analyze an individual-based model in which complex ecological communities emerge through the repeated evolutionary branching of trophic traits driven by the underlying ecological interactions. In our model, individuals are characterized by two quantitative traits that determine, respectively, predation ability and predation vulnerability. The eco-evolutionary community dynamics unfold through the succession of stochastic birth and death events (Gillespie 1976). Reproduction is asexual, and during each birth event quantitative traits may undergo mutations of small effect with a small probability. The rates at which birth and death events occur are determined by the intensity of interference competition and predation among individuals.

Unexpectedly, we find that the structure of the evolving community does not settle toward an equilibrium, but instead cyclically alternates between two meta-stable states (Figure 1). One state is characterized by a diverse assembly of primary producers (plants), whereas the other state features a collection of primary producers exploited by specialized consumers (herbivores). These two meta-stable states are connected through unidirectional transitions: coevolutionary diversification of producers and consumers, and cascading extinction of producers and consumers. In a meta-stable community with diverse primary producers and matched consumers, the emergence of an additional consumer species through evolutionary branching can destabilize the producer community and, thus, trigger a cascade of extinctions. The implied sharp reduction in species richness is followed by the coevolutionary diversification of producers and consumers, resulting in an increase in species richness until the second meta-stable community state is reached, whence another evolutionary community cycle starts.

\section{Acknowledgements}

We thank Shigeo Yachi, Norio Yamamura, and Arndt Telschow for valuable discussions, and

Maurice W. Sabelis for helpful comments and suggestions. This work was partially supported by the

Global COE Program A06 to Kyoto University and JSPS Core-to-Core Program, 20004.

\section{References}

Drossel B, Higgs PG, McKane AJ. 2001. The influence of predator-prey population dynamics on the long-term evolution of food web structure. J Theor Biol 208:91-107 
long-term evolution of food web structure. J Theor Biol 229:539-548

Gillespie DT. 1976. A general method for numerically simulating the stochastic time evolution of coupled chemical reactions. J Comput Phys 22:403-434

Ito HC, Ikegami T. 2006. Food-web formation with recursive evolutionary branching. J Theor Biol 238:1-10

Ito HC, Shimada M, Ikegami T. 2009. Coevolutionary dynamics of adaptive radiation for food-web development. Popul Ecol 51:65-81

Rossberg AG, Brännström Å, Dieckmann U. 2010a. Food-web structure in low- and high-dimensional trophic niche spaces. J R Soc Interface 7:1735-1743

Rossberg AG, Brännström Å, Dieckmann U. 2010b. How trophic interaction strength depends on traits: a conceptual framework for representing multidimensional trophic niche spaces. Theor Ecol 3:13-24

Rossberg AG, Matsuda H, Amemiya T, Itoh K. 2006. Food webs: experts consuming families of experts. J Theor Biol 241:552-563

Rossberg AG, Ishii R, Amemiya T, Itoh K. 2008. The top-down mechanism for body-mass-abundance scaling. Ecology 89:567-580

Troost TA, Kooi BW, Dieckmann U. 2008. Joint evolution of predator body size and prey-size preference. Evol Ecol 22:771-799

Yoshida K. 2006. Ecosystem models on the evolutionary time scale: a review and perspective. Paleontol Res 10:375-385 


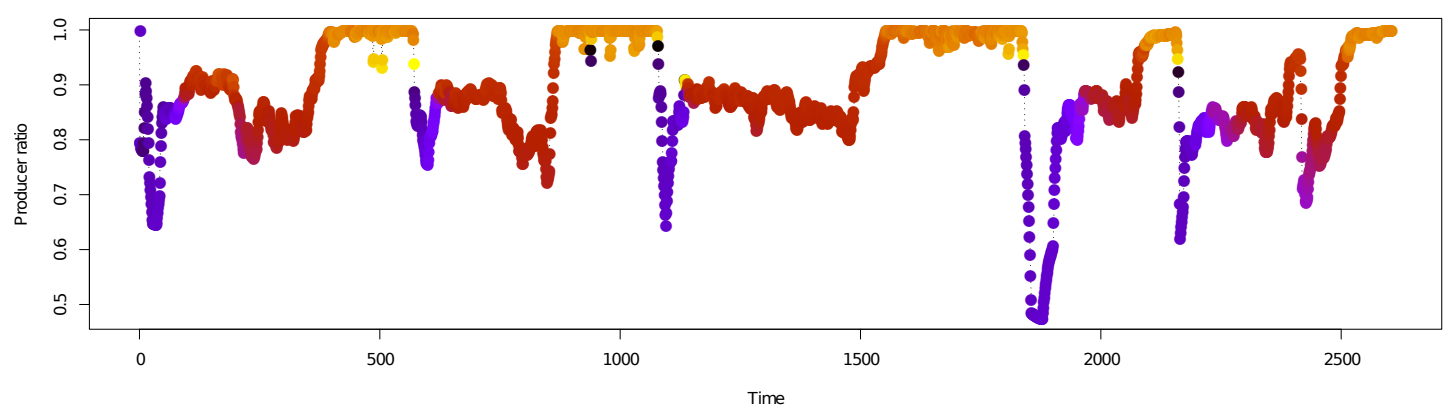

84 Figure 1. Changes in producer ratio (producer biomass per total biomass, measured across the entire community) caused by the modeled eco-evolutionary community dynamics. Two meta-stable states can be distinguished, corresponding to producer ratios of nearly 1 and approximately 0.8 . In the latter case, producers coexist with consumers. Sharp increases and decreases of the producer ratio indicate the rapid transitions between the two meta-stable community states. 